\title{
Erratum to: Some Graphs with Double Domination Subdivision Number Three
}

\author{
Haoli Wang • Xirong Xu • Yuansheng Yang • \\ Baosheng Zhang
}

Published online: 29 January 2013

(C) Springer Japan 2013

\section{Erratum to: Graphs and Combinatorics DOI 10.1007/s00373-012-1254-z}

The authors would like to modify the footnote published in the first page of the original publication as given below:

The research is supported by Chinese Natural Science Foundations (11226280, 60973014, 61170303) and Doctoral Fund of Tianjin Normal University (52XB1202).

The online version of the original article can be found under doi:10.1007/s00373-012-1254-z.

\section{H. Wang}

College of Computer and Information Engineering, Tianjin Normal University,

Tianjin 300387, China

X. Xu · Y. Yang $(\varangle) \cdot$ B. Zhang

Department of Computer Science, Dalian University of Technology,

Dalian 116024, China

e-mail: yangys@dlut.edu.cn 